\title{
Effect of the thickness distribution and setting condition on springback in multi-layer sheet bending
}

\author{
S. V. Mohammadi ${ }^{1}$, M. H. Parsa ${ }^{2}$, A. Jalali Aghchai ${ }^{3}$ \\ ${ }^{I}$ Department of Mechanical Engineering, School of Engineering and Hi-tech, Iran University of Industries and Mines, Tehran, IRAN \\ ${ }^{2}$ School of Metallurgy and Materials Engineering, College of Engineering, University of Tehran, IRAN \\ "Corresponding Author: e-mail: svmohammadi@ hitech.iuim.ac.ir, Tel +98-9367384358
}

\begin{abstract}
The new industrial demands for special materials with better properties have led to the invention of composite materials. Twolayer clad sheets and three-layer sandwich sheets are increasingly applied in vast range of industrial application due to their remarkable characteristics. In this paper springback -which is an undesirable phenomenon- in sheet metal bending was studied in two-layer clad sheets and three-layer sandwich sheets. First based on bending theory, springback of a multi-layer sheet was discussed analytically. Then, the effect of layers' thicknesses and setting condition on springback were studied and then Genetic Algorithm (GA) was applied in order to minimize springback in certain setting condition. FEM simulation of sandwich sheet four-point bending was also performed in order to verify analytical results and GA output. Considering both analytical and FEM approaches, it was observed that springback can be reduced with the change in layers' thicknesses and layers' configuration.
\end{abstract}

Keywords: clad sheet, sandwich sheet, bending, springback, genetic algorithm, FEM

\section{Introduction}

In recent years, new technologies are expected to respond to new industrial demands. These demands, mostly seek saving the materials and upgrading the mechanical, electrical and thermal characteristics of the product. In sheet metal industries bi-layer clad and three-layer metal/polymer/metal laminated sheets are increasingly applied in automotive and aircraft industries due to their characteristics such as high stiffness/weight ratio, vibration damping and special thermal and electrical behavior (Danesh Manesh and Taheri, 2003 and Rao, 2003). Clad sheet forming was studied by several authors. In deep drawing and redrawing processes it has been shown that differences in material properties, thickness ratio of the layers and also setting condition, that shows which side of the sheet contacts the punch or die, are important parameters in fracture and springback behavior of Steel/Aluminium clad sheets (Parsa et al., 2001 and Hino et al., 2003). Springback prediction of stainless steel/ aluminum clad sheets was also investigated (Yilamu et al., 2010). It was observed that the thickness ratios and the setting conditions affect sheet bending behavior such as springback and sheet thinning. Primary analytical springback analysis in multilayer sandwich sheets has also been performed using Tresca criterion in pure bending (Ito et al., 1981, Lio and Wang, 2004 and Yuen, 1996). It was mentioned that springback would be changed by changing the layers' thicknesses. Results showed that springback can be decreased when internal layers of the bend thicken (Lio and Wang, 2004). Sheet metal forming optimization has been investigated using Genetic algorithm. Cold stretch forming parameters were optimized using integrated Analytical-Finite Element (FEM)-GA methods to minimize springback (De-hua et al., 2010). V-bending and U-bending processes parameters were optimized in order to obtain the minimum springback, applying combined FEM-GA methods (Sousa et al., 2006).

In this paper first an analytical model was applied for springback prediction. Then the influence of thickness distribution and setting condition on the springback was studied in three- layer sandwich sheets and bi- layer clad sheets. Then genetic algorithm was used to obtain layers' thicknesses in order to minimize amount of the springback in a certain setting condition in pure bending process. FEM simulation of four-point bending was performed in order to verify results of analytical procedure and GA outputs. Results show that in sandwich sheets with increase in internal layer thickness springback decreases, while in clad sheets, minimum springback is obtained when sheets tend to be single layer rather than bi-layer. 


\section{Analytical Springback Model and Formulation}

Primary bending theory and von Mises yield criterion were used to derive springback formulation. In bending of multi-layer sheets, different layers may undergo elastic-plastic deformation. Elastic recovery of different layers causes the springback of multilayer sheet. A suitable model should be considered for analyzing the springback using analytical method. Figure 1 shows a multi-layer sheet model consists of 4-layer which is subjected to pure bending. In such condition the circumferential strain at radius $r$ can be calculated using equation (1).

$$
\varepsilon_{\theta}=\left(r-R_{n}\right) / R_{n}
$$

Where $R_{n}$ is the radius of curvature of the neutral fiber and it is assumed that it is large when compared with the sheet thickness. Elastic stress can be derived using Hook's law as shown in equation (2).

$$
\sigma_{\theta}=E\left(r-R_{n}\right) /\left(1-v^{2}\right) R_{n}=E^{\prime}\left(r-R_{n}\right) / R_{n}
$$

Where $\dot{\mathbf{E}}$ is the elasticity modulus in plane strain bending. In the plastic state, considering von Mises yield criterion and plastic flow rule, equivalent stress and equivalent strain can be related to the circumferential stress and stain as shown in equation (3) (Marciniak Z. and Duncan J., 1992).

$$
\begin{aligned}
& \bar{\sigma}=\frac{\sqrt{3}}{2} \sigma_{\theta} \\
& \bar{\varepsilon}=\frac{2}{\sqrt{3}} \varepsilon_{\theta}
\end{aligned}
$$

Holloman equation is considered to describe isotropic strain hardening $\left(\bar{\sigma}=k \bar{\varepsilon}^{n}\right)$, so circumferential stress can be related to radial position of layers as illustrated by equation (4) (Marciniak Z. and Duncan J., 1992).

$$
\sigma_{\theta}=\left(\frac{2}{\sqrt{3}}\right)^{n+1} k\left(\frac{r-R_{n}}{R_{n}}\right)^{n}
$$

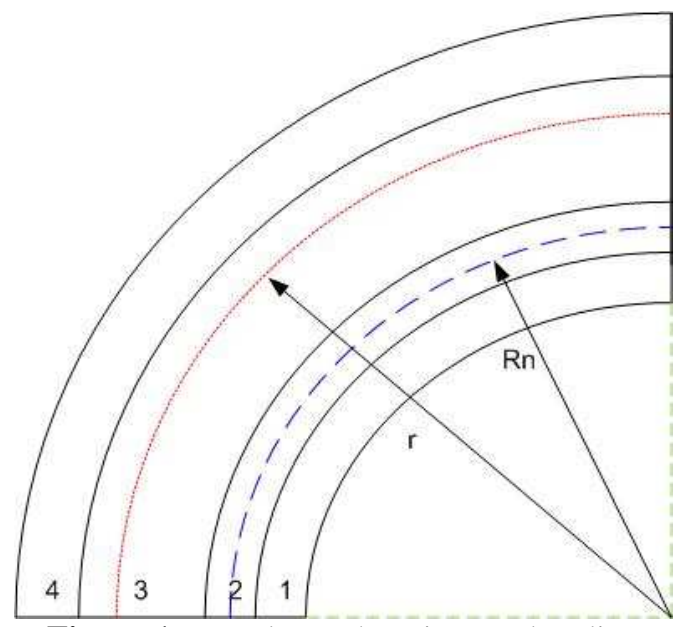

Figure 1. Four-layer sheet in pure bending 


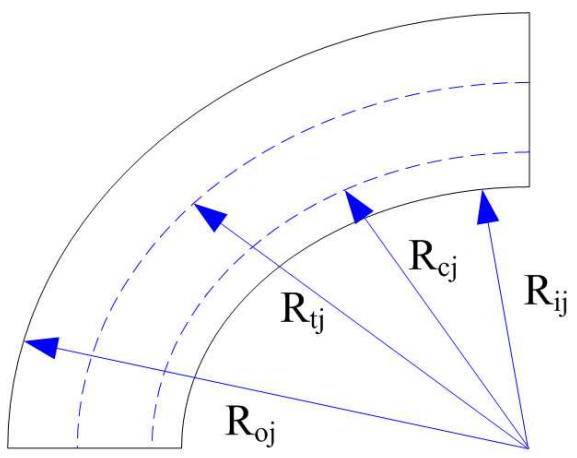

Jth Layer

Figure 2. Fibers in which jth layer yields to tensile and compressive stress, and inner and outer radiuses of jth layer

$R_{t j}$ and $R_{c j}$, as shown in figure 2, are the radii in which jth layer yields in tensile and compressive stresses respectively. They can be calculated using equation (5).

$$
\begin{gathered}
\varepsilon_{c j}=\frac{R_{c j}-R_{n}}{R_{n}}=\frac{-\left(\frac{2}{\sqrt{3}}\right) Y_{j}}{E_{j}^{\prime}} \rightarrow R_{c j}=R_{n}\left(1-\frac{\left(\frac{2}{\sqrt{3}}\right) Y_{j}}{E_{j}^{\prime}}\right) \\
\varepsilon_{t j}=\frac{R_{t j}-R_{n}}{R_{n}}=\frac{\left(\frac{2}{\sqrt{3}}\right) Y_{j}}{E_{j}^{\prime}} \rightarrow R_{t j}=R_{n}\left(1+\frac{\left(\frac{2}{\sqrt{3}}\right) Y_{j}}{E_{j}^{\prime}}\right)
\end{gathered}
$$

Where $\mathrm{Y}_{\mathrm{j}}$ is yield stress of the jth layer. If $R_{i j}$ and $R_{o j}$ are the inner and outer radius of jth layer respectively, plastic compressive range $\left[R_{i j}, C_{j}\right]$, elastic range $\left[C_{j}, D_{j}\right]$ and plastic tensile range $\left[D_{j}, R_{o j}\right]$ for jth layer can be considered as shown in equation (6).

$$
\begin{gathered}
C_{j}=\left\{\begin{array}{lcr}
R_{i j} & \text { if } & R_{c j} \leq R_{i j} \\
R_{c j} & \text { if } & R_{i j}<R_{c j}<R_{o j} \\
R_{o j} & \text { if } & R_{c j} \geq R_{o j}
\end{array}\right. \\
D_{j}=\left\{\begin{array}{llr}
R_{i j} & \text { if } & R_{t j} \leq R_{i j} \\
R_{t j} & \text { if } & R_{i j}<R_{t j}<R_{o j} \\
R_{o j} & \text { if } & R_{t j} \geq R_{o j}
\end{array}\right.
\end{gathered}
$$

Considering $\boldsymbol{m}$-layer sheet, the total force and moment in sheet cross section $(1, \ldots, \mathrm{j}, \ldots, \mathrm{m})$ can be calculated using equations $(7)$ and (8).

$$
\begin{gathered}
f=\int_{R_{i 1}}^{R_{o m}} \sigma_{\theta} d r=\sum_{j=1}^{m}\left(\int_{R_{i j}}^{c_{j}} \sigma_{c p j} d r+\int_{c_{j}}^{D_{j}} \sigma_{e j} d r+\int_{D_{j}}^{R_{o j}} \sigma_{t p j} d r\right)=0 \\
M=\int_{R_{i 1}}^{R_{o m}} \sigma_{\theta}\left(r-R_{n}\right) d r=\sum_{j=1}^{m} \int_{R_{i j}}^{c_{j}} \sigma_{c p j}\left(r-R_{n}\right) d r+\int_{c_{j}}^{D_{j}} \sigma_{e j}\left(r-R_{n}\right) d r+\int_{D_{j}}^{R_{o j}} \sigma_{t p j}\left(r-R_{n}\right) d r=0
\end{gathered}
$$

Where $\sigma_{e j}, \sigma_{c p j}$ and $\sigma_{t p j}$, are elastic, compressive plastic and tensile plastic stresses in jth layer respectively which can be calculated using equations (2) and (4). The neutral layer radius of curvature can be found using equation (7) noticing that in pure bending the total force through thickness should be equal to zero.

\subsection{Springback}

Springback is an elastic recovery after forming process that changes product's geometry. During loading, internal radius of first layer is considered as a known parameter, since it equals the punch radius. After unloading, not only the internal radius changes but also the neutral radius is changed; so a procedure should be applied in order to find both $\mathrm{R}^{\prime}{ }_{\mathrm{i} 1}$ and $R^{\prime}{ }_{n}$, respectively. Force and moment equilibrium equations are usually considered to calculate these unknown parameters. Considering springback as an elastic process, it is common to assume that elastic moment differentiation equals bending moment (Marciniak Z. and Duncan J., 1992). Also force equilibrium should be satisfied after forming; So equations 9 and 10 can be derived. 


$$
\begin{array}{r}
f=\int_{R_{i 1}^{\prime}}^{R_{o m}^{\prime}} \sigma_{\theta}^{\prime} d r=\sum_{j=1}^{m} \int_{R_{i j}^{\prime}}^{R_{o j}^{\prime}} \sigma_{e j}^{\prime} d r=0 \\
\Delta M=\int_{R_{i 1}^{\prime}}^{R_{o m}^{\prime}} \Delta \sigma_{\theta}^{\prime}\left(r-R_{n}^{\prime}\right) d r=\sum_{j=1}^{m} \int_{R_{i j}^{\prime}}^{R_{o j}^{\prime}} \Delta \sigma_{e j}^{\prime}\left(r-R_{n}^{\prime}\right) d r=M
\end{array}
$$

Where $\Delta \dot{\sigma}_{v j}$, is the change in elastic stress in jth layer after unloading and it can be calculated based on equation (11).

$$
\Delta \sigma_{e j}^{\prime}=E^{\prime}\left(\frac{r-R_{n}}{R_{n}}-\frac{r-R_{n}^{\prime}}{R_{n}^{\prime}}\right)
$$

Using equation (9) and (10), neutral fiber can be calculated after unloading. Knowing the position of neutral fiber, before and after unloading, normalized spring back, which in parametric studies it can better depict the springback behavior than unnormalized one, can be found using equation (12).

$$
\eta=\frac{\Delta \theta}{\theta}=\frac{\Delta\left(\frac{1}{R_{i}}\right)}{\frac{1}{R_{i}}}
$$

The neutral fibre position can be calculated for both forming and springback stages using derived formulations and converting them into a computer program. Figure 3 shows the developed and implemented algorithm to find the neutral fibre for a $m$-layer sheet. In computer programming Bi-section method was applied to find unknown parameters. It worth to mention that internal bending radius in analytical approach is considered to be equal to $16.5 \mathrm{~mm}$; therefore primary bending theory which ignores sheet thinning and transverse stress can be assumed accurately (Marciniak Z. and Duncan J., 1992).

\section{Finite Element Method}

In order to verify analytical results, implicit finite element analysis was performed on plain strain Four-point bending of Al3105/Polypropylene/Al3105 using commercially available software. In four-point bending, shown in Figure 4, there is uniform moment acting on the sheet in punch region and so results from four-point bending can be accurately used to compare with analytical pure bending results. Figure 4(b) shows FEM model of sandwich sheet four-point bending. Due to the symmetry only half of the die is modeled. Geometrical variables such as die radius, punch tip radius and distance between punch tips are considered by try and error in such a way that the internal bending radius equals to $16.5 \mathrm{~mm}$ as shown in Figure 5 (a).

Material properties derived from uni-axial tension tests are used in the calculations as stated in Table 1. It is assumed there is no shear between adjacent layers. After performing mesh sensitivity analysis, model was meshed using 3600 linear elements with 10 elements in the thickness direction. Punch slightly strokes in several steps in order to make a smooth contact with the sheet, avoiding considerable change in contact zone. Punch and die were modeled as rigid bodies and after performing mesh sensitivity analysis finer mesh was considered in punch-sheet and die-sheet local contact areas in order to avert difficulties in contact equation convergence. For springback simulation, after forming stage, punch is gradually brought back to its initial position while springback happens in the sheet.

For calculating normalized springback, internal fiber radius should be calculated using finite element results. Data points at different sections in the punch tip-sheet contact zone are considered as shown in Figure 5. Coordinates of these selected points were considered as a set of data points and an arc of a circle was fitted to data points. Arc radius was then considered as internal fiber radius. This procedure was applied in both forming and springback stages for the same sections. 


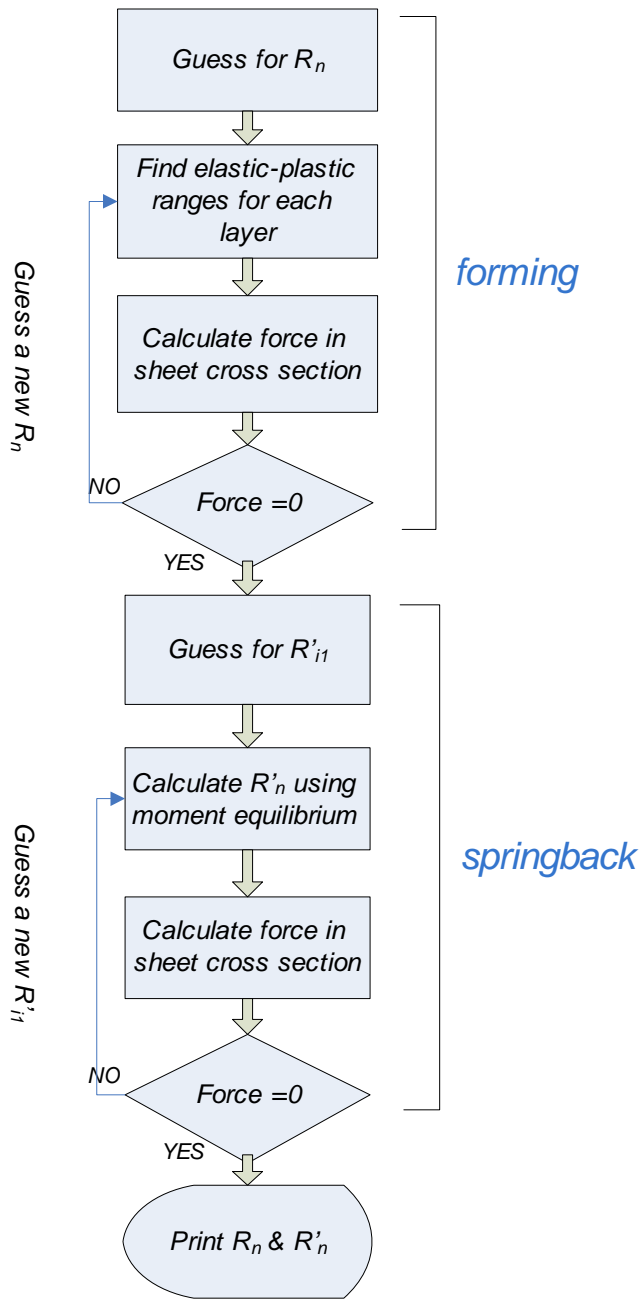

Figure 3. Applied algorithm to find neutral fibers before and after springback

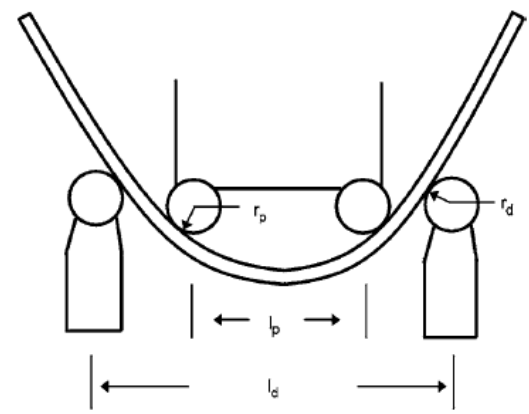

(a)

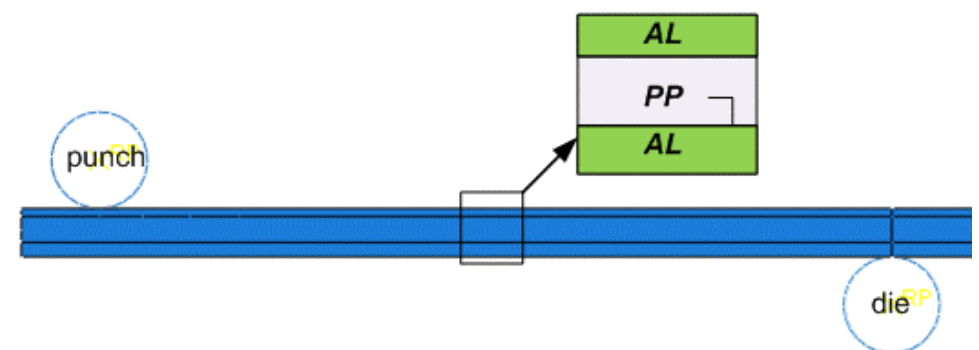

(b)

Figure 4. (a) four-point bending process, (b) FEM model for sandwich sheet four-point bending 


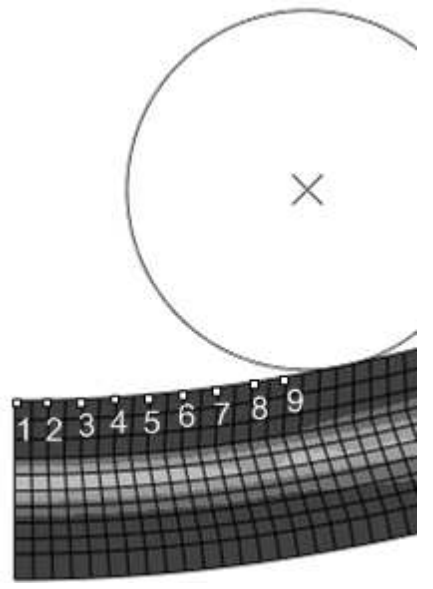

(a)

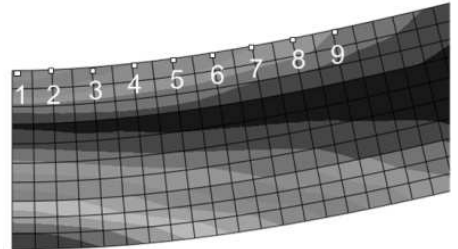

(b)

Figure 5. Internal fiber radius calculation using data points (a) before unloading, (b) after unloading.

\section{Genetic Algorithm}

Springback is a complicated phenomenon relying on several parameters of the bending process encompassing mechanical properties of the material, frictional condition and geometrical properties of the bend. In multi-layer sheet bending these effects are more complicated, since there are inter-layer interactions affected by layers' thicknesses and setting condition. Therefore prediction of parameters effects on the springback become complicated and it is necessary to optimize them for minimum springback. Genetic Algorithm (GA) is an optimization algorithm which follows the basis of genetics and natural selection. Optimized solution is derived by choosing a random set of possible answers in the space of results. These initial answers are the populations of the first generation. Then GA improves answers in the next generation by first, natural selection among best individuals as parents and then, combining the fittest answers and making new offspring. Fitness function determines how appropriate the answers are and makes parents selection possible for the next generation. GA attains the optimized solution by repeating this process in several generations. GA surpasses conventional optimization algorithms due to its advantages, since it can optimize with discrete and continuous variables and it does not require derivative information (Haupt et al., 2004). In this paper the GA was applied to optimize layers' thickness and setting conditions for minimizing springback in the bending process of threelayer A13105/Polypropylene/A13105 laminated sheet and A13105/St14 clad sheets using MATLAB GA and Direct Search Toolbox. The mechanical properties of the materials are shown in Table 1 . They were derived by uni-axial tensile tests using a screw driven Instron universal testing machine with a cross-head velocity of $5 \mathrm{~mm} / \mathrm{min}$ based on ASTM B 577M.

Table1. Al3105, Polypropylene and St14 mechanical properties

\begin{tabular}{|c|c|c|c|c|c|}
\hline Material & $\begin{array}{ll}\begin{array}{l}\text { Elasticity } \\
\text { (Gpa) }\end{array} & \text { modulus } \\
\end{array}$ & Poisson ratio & $\begin{array}{l}\text { Yield strength } \\
\text { (Mpa) }\end{array}$ & $\begin{array}{l}\text { Strain hardening } \\
\text { power }\end{array}$ & Strength coefficient (Mpa) \\
\hline $\mathrm{Al} 3105$ & 70 & 0.33 & 120 & 0.074 & 241 \\
\hline Polypropylene & 1.5 & 0.4 & 3.7 & 0.474 & 100 \\
\hline St14 & 200 & 0.3 & 220 & 0.27 & 625 \\
\hline
\end{tabular}
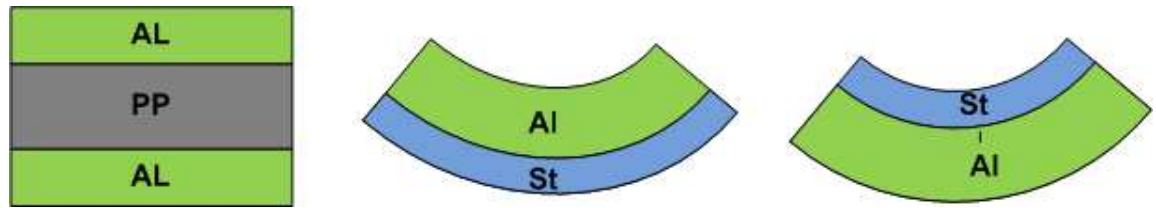

Figure 6: (a) Al/PP/Al sheet, (b) Al/St setting condition, Al layer contacts punch, (c) St/Al setting condition, St layer contacts punch. 


\section{Results and discussion}

Based on the mechanical properties presented in Table 1, optimized thickness distribution for clad sheet was studied in two different setting conditions, namely St/Al and Al/St. For Al/PP/Al sheets, only the thickness distribution was investigated since it makes no sense to study setting conditions, due to the symmetric configuration. Figure 4 shows the different multi-layer sheets under analysis. The layers are named from the inner to the outer layer, e.g. in figure 6(b) Al is the first layer and St is the second layer. Total thickness of clad and sandwich sheets were constrained to $2 \mathrm{~mm}$ and layers' thickness distribution was derived to minimize springback. Thickness distribution was studied for Al/PP/Al sandwich sheet. Figure 7 shows how GA converged to minimum normalized springback. Layers' thicknesses were considered as variables and theoretical springback formulation was considered as the fitness function. In Figure 7, no constraint was assumed for total thickness and each layer could vary between 0 to $2 \mathrm{~mm}$.

Figure 7 shows that difference between mean and best fitness decreases with generation. Two reasons can be used for explanation of this behavior. First, based on natural selection best individuals survive to stay at next generations and second, offspring are produced by combining best individuals. Also from Figure 7 it can be observed that some points are far from the best fitness; this is due to mutation operator which changes amount of some individuals in a current generation, avoiding GA to be trapped in local minima.

Before applying GA in order to find optimized Al/PP/Al thickness configuration -which results in minimum springback in laminated sheet- with the constraint of $2 \mathrm{~mm}$ as the total thickness, it is better to study the outline of the effect of thickness change on springback. Table 2 presents the description of configuration labelled from a to e, as well as the normalized springback for each of the configurations using both analytical and FEM approaches.

Configurations a and $b$ of Table 2 show the effect of setting condition on normalized springback when one layer is omitted. It is clear that springback in Al/PP is less than PP/Al. Configurations $\mathrm{c}$ and d of Table 2 illustrates mono-layer aluminium sheet shows less springback than mono-layer polymeric sheet. When PP is used as a core for sandwich sheet, springback decreases (Table 2, configuration e).

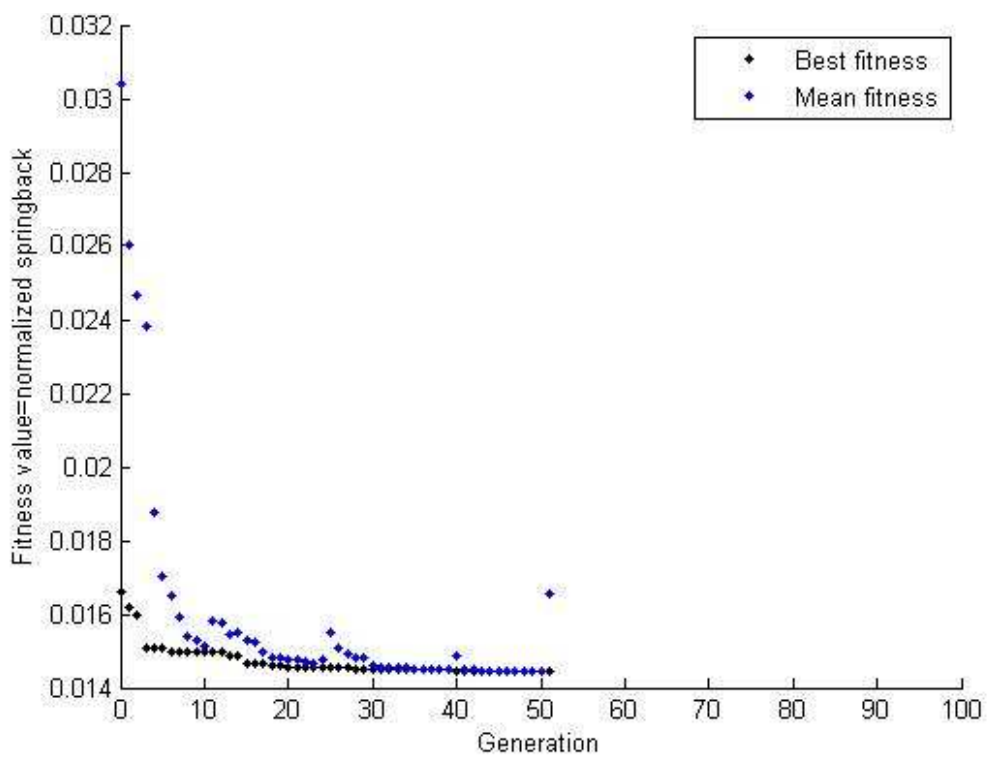

Figure 7. Genetic algorithm convergence after 52 generations

Table 2. Influence of thickness configuration on springback in Al/PP/Al laminated sheet

\begin{tabular}{|c|c|c|c|c|c|c|}
\hline \multicolumn{2}{|c|}{ Configuration } & $\mathrm{a}$ & $\mathrm{b}$ & $\mathrm{c}$ & $\mathrm{d}$ & $\mathrm{e}$ \\
\hline AL & $\mathrm{t} 1(\mathrm{~mm})$ & 1 & 0 & 2 & 0 & 0.5 \\
\cline { 2 - 7 } $\mathrm{PP}$ & $\mathrm{t} 2(\mathrm{~mm})$ & 1 & 1 & 0 & 2 & 1 \\
\hline AL & $\mathrm{t} 3(\mathrm{~mm})$ & 0 & 1 & 0 & 0 & 0.5 \\
\hline Normalized springback (anal.) & 0.169 & 0.184 & .0774 & 0.393 & .0692 \\
\hline Normalized springback(FEM) & 0.181 & 0.196 & .0794 & 0.423 & .0761 \\
\hline
\end{tabular}




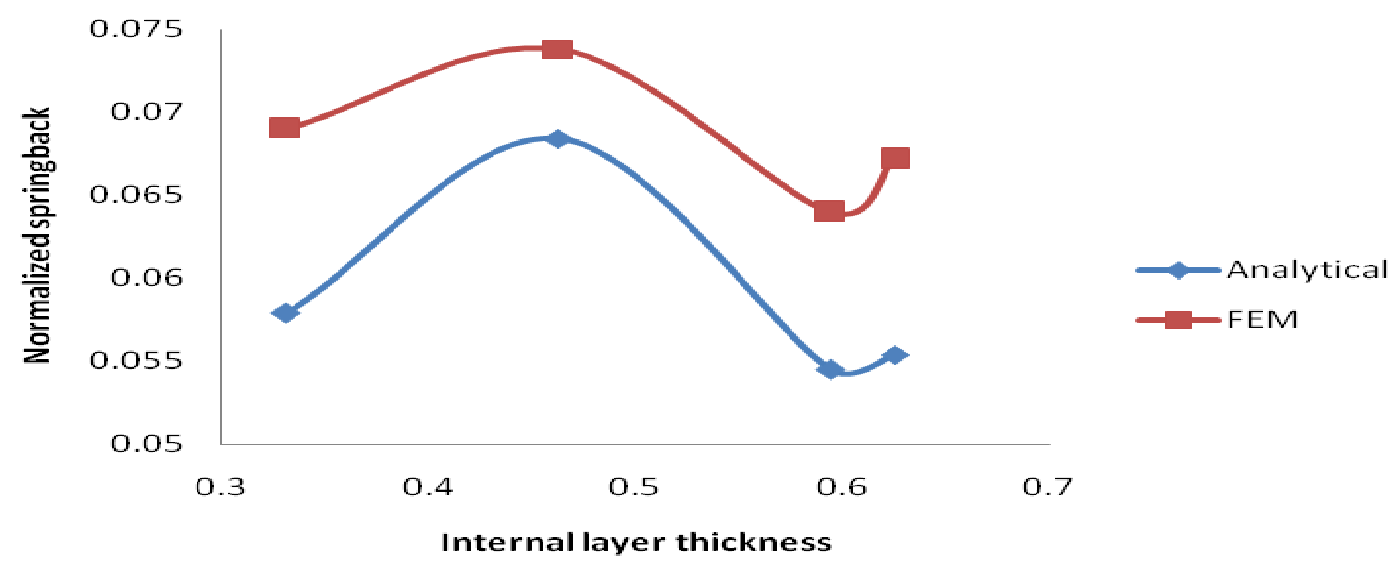

Figure 8. Normalized springback change with internal layer thickness

This effects can be explained by contraction the effects of mechanical properties on springback. In Table 1 it can be seen that polypropylene has lower elasticity modulus and yield strength than Al. Springback increases with the yield strength and decreases with the elasticity modulus (Marciniak and Duncan, 1992); hence adding polymeric core between two skins of Al may decrease springback comparing with mono-layer aluminium with the same total thickness. It can be observed from Table 2 that both analytical and FEM approaches show the same trend in springback behavior.

In order to determine the thickness distribution in Al/PP/Al laminated sheet that minimizes the amount of springback the GA was applied, considering a punch radius of $16.5 \mathrm{~mm}$. Table 3 shows the output of the GA when the total thickness is limited to 2 $\mathrm{mm}$ and the thickness of each layer can vary between 0 to $2 \mathrm{~mm}$. Table 3 shows that with increase in the internal layer of the bend, springback decreases. The same results were observed in previous studies (Li et al., 2004). They mentioned that with the increase in internal layer thickness and decrease in external layer thickness, springback decreases. In symmetric sandwich sheet where thickness uniformly distributed between internal and external layers ( $1=\mathrm{T} 3=0.4625 \mathrm{~mm})$, normalized springback is 0.0684 . Therefore with no change in total thickness and sheet weight, springback reduces about $25 \%$ with the change in thickness distribution.

FEM simulation was applied in order to verify analytical results. Skins' thicknesses changed and core thickness remains constant equal to $1.075 \mathrm{~mm}$ and simulation was performed. Figure 8 show both analytical and FEM results. It can be observed that with increase in internal layer thickness springback first increases, then decreases and again increases. Analytical and FEM results show that the minimum amount of springback can be achieved when thickness distribution is chosen the same as Table 3 .

Table 3:GA output for layers' thickness in constrained optimization

\begin{tabular}{|l|c|c|c|}
\hline Layers' thickness & $\mathrm{t} 1$ & $\mathrm{t} 2$ & $\mathrm{t} 3$ \\
\hline Optimal amount $(\mathrm{mm})$ & 0.594 & 1.075 & 0.331 \\
\hline \multicolumn{2}{|c|}{ Minimal Normalized Springback } & 0.0545 \\
\hline
\end{tabular}

For clad sheets when total thickness was limited to $2 \mathrm{~mm}$ and each layer can vary between 0 to $2 \mathrm{~mm}$, GA program obviously converged to the thickness of $2 \mathrm{~mm}$ for steel and $0 \mathrm{~mm}$ for $\mathrm{Al}$ in both Al/St and St/Al setting conditions; because steel shows less springback than aluminium. Applying GA to find the optimized thickness of layers in both setting conditions namely St/Al and $\mathrm{Al} / \mathrm{St}$, when there were constraints on each layer's thickness, it was observed that in both setting conditions normalized springback was minimized when steel layer had the maximum possible thickness. To describe this behavior, bending behavior of clad sheets was studied considering punch radius of $16.5 \mathrm{~mm}$ and total thickness constraint of $2 \mathrm{~mm}$. Due to differences in mechanical properties of layers; neutral fiber radius differs with the change in layers' thickness and setting conditions.

Figure 9 shows the neutral fiber radius evolution with the change of steel and/or aluminium thickness- total thickness of steel and aluminium layers should equal $2 \mathrm{~mm}$ - in both Al/St and St/Al setting conditions. For St/Al setting condition, when the steel layer has a thickness less than around $0.9 \mathrm{~mm}$, the neutral fiber lays in the aluminium layer; but thickening of steel layer causes of shifting neutral layer into the steel layer. For Al/St configuration, neutral layer coincides with aluminium layer, when steel layer has the thickness less than around $1.2 \mathrm{~mm}$; while thickening steel layer leads to the movement of neutral layer into steel layer. It is also clear from Figure 9 that in both mono-layer aluminium and steel sheets neutral fiber coincides with mid plane with the neutral fiber radius of $17.5 \mathrm{~mm}$. Figure 10 shows neutral fiber radius after unloading. As can be seen from Figure 10 when mono-layer sheet is made up of $2 \mathrm{~mm}$ of $\mathrm{Al}$, neutral fiber radius is higher, comparing with $2 \mathrm{~mm}$ mono-layer steel sheet and consequently springback in $\mathrm{Al}$ sheet is more than springback in steel sheet. Same inferences could be made about the position of the neutral fiber after unloading in both setting conditions. Figure 11 shows normalized springback with the change in the thickness of steel layer in both St/Al and Al/St setting conditions. As can be seen in Figure 11, in both setting conditions for $2 \mathrm{~mm}$ clad sheets, when the steel layer thickness decreases, normalized springback increases and when steel layer thickness increases, springback decreases. It 
is also clear that when St/Al thickness ratio is too high or too low, amounts of springback in both setting conditions are too close but when this ratio is around 1 springback differs in $\mathrm{St} / \mathrm{Al}$ and $\mathrm{Al} / \mathrm{St}$ setting conditions.

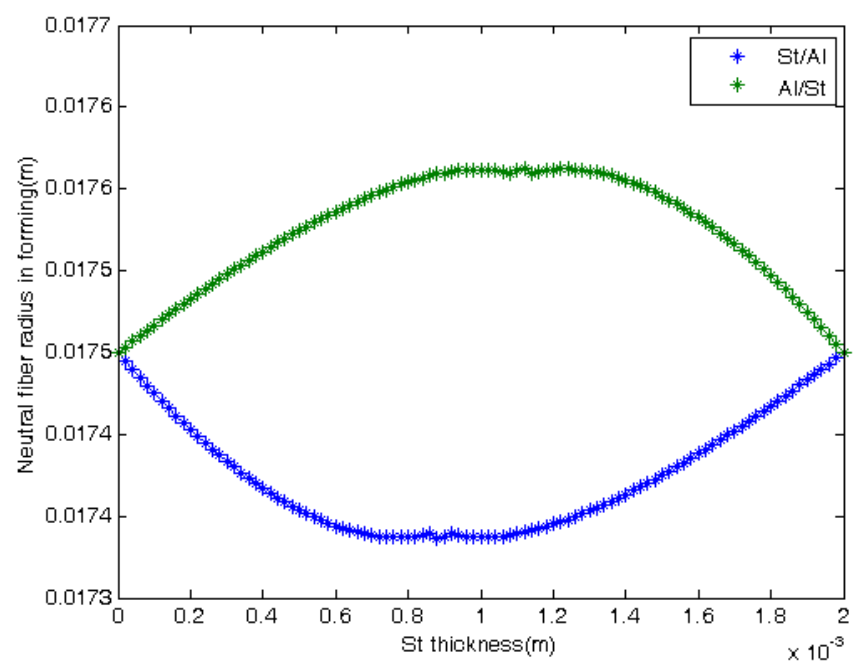

Figure 9. Neutral fiber radius change with steel layer thickness change in $\mathrm{St} / \mathrm{Al}$ and $\mathrm{Al} / \mathrm{St}$ clad sheets

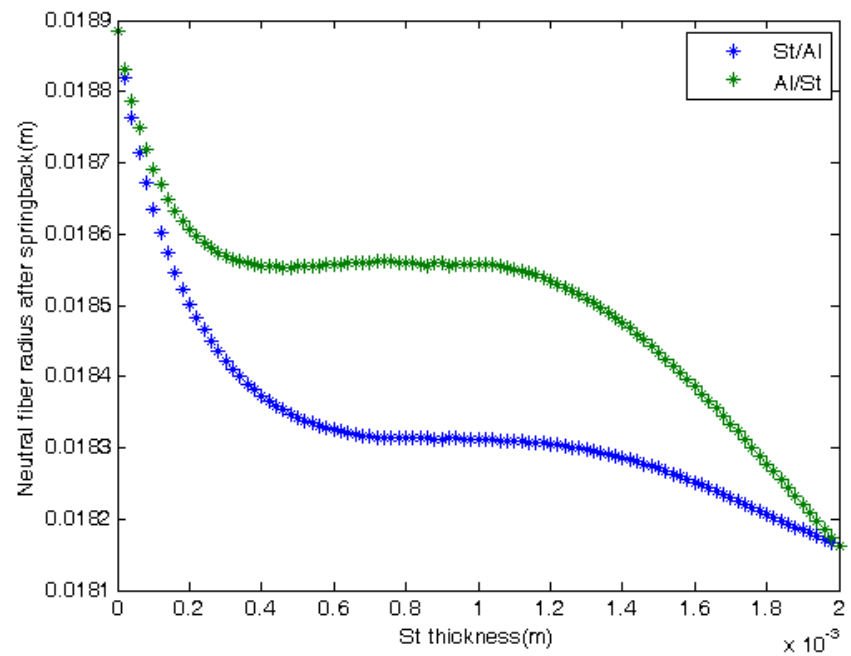

Figure 10. Neutral fiber radius change with steel layer thickness change in $\mathrm{St} / \mathrm{Al}$ and $\mathrm{Al} / \mathrm{St}$ clad sheets

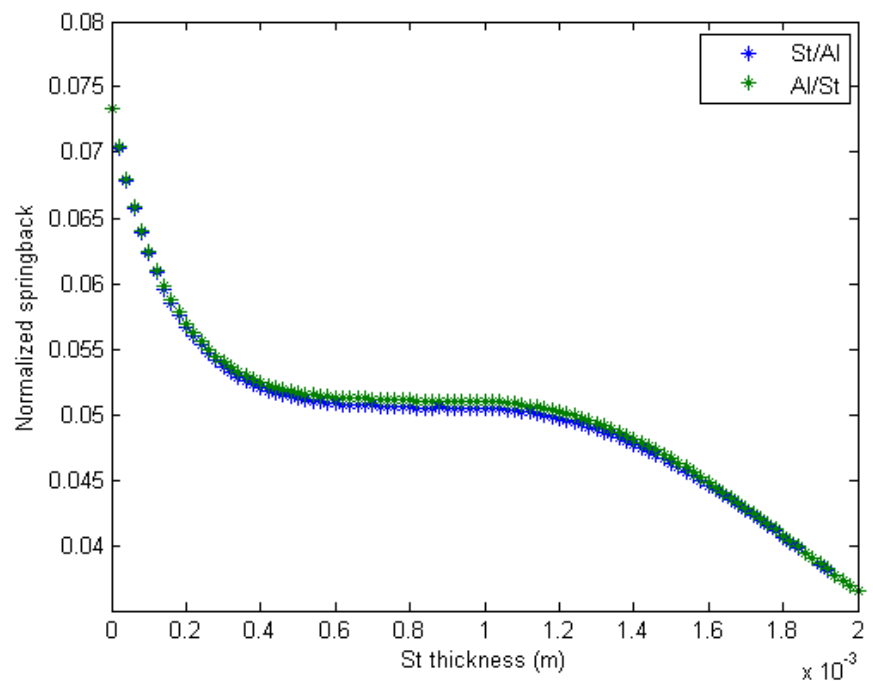

Figure 11. Normalized springback change with layers' thickness change in St/Al setting condition 


\section{Conclusion}

Theoretical Springback prediction in two-layer aluminium/steel clad sheets and three-layer aluminium/polypropylene/aluminium laminated sheets was studied in pure bending using primary bending theory. Variations in layers' thicknesses and their relative positions, namely setting condition, were studied. Results showed that the thickness distribution and setting condition have remarkable effect on bending and springback behavior of multi-layer sheets. In clad sheets neutral fiber radius, before and after unloading, differs with relative thickness of the layers and setting conditions; but normalized springback differs just with relative thickness of the layers and almost the same behavior is observed in both St/Al and Al/St setting conditions. A genetic algorithm was applied in order to find the optimized relative thickness of the layers, according the imposed setting conditions. In Al/PP/Al laminated sheet, it was observed that when the inner layer of the bend thickens, normalized springback reduces about $25 \%$ comparing with symmetrical sandwich sheet. In clad sheets, apart from setting conditions, GA converged to the minimum amount of springback when steel layer has the highest possible thickness. Combining theoretical and genetic algorithm layers' configuration and thicknesses can be found to reach to the minimum springback. FEM simulation of four point bending was performed on sandwich sheet. It is observed that both analytical and FEM approaches, correlates well, obtaining the optimized distribution in skin-core thicknesses.

\section{Nomenclature}

$\begin{array}{ll}\varepsilon_{\theta} & \text { Circumferential strain } \\ \sigma_{\theta} & \text { Circumferential stress } \\ E & \text { Elasticity modulus } \\ E^{\prime} & \text { Elasticity modulus in plane strain } \\ v & \text { Poisson ratio } \\ \bar{\sigma} & \text { Equivalent stress } \\ \bar{\varepsilon} & \text { Equivalent strain } \\ k & \text { Strength coefficient } \\ n & \text { Hardening power } \\ r & \text { Arbitrary radius } \\ R & \text { Neutral fibber } \\ Y & \text { Yield strength } \\ \varepsilon_{t} & \text { Strain in which sheet yields in tension } \\ \varepsilon_{c} & \text { Strain in which sheet yields in compression } \\ R_{i} & \text { inner radius } \\ R & \text { Outer radius } \\ f & \text { Force per width unit in sheet cross section } \\ M & \text { Moment per width unit in sheet cross section } \\ j & \text { Subscription for jth layer } \\ \eta & \text { Nending angle } \\ & \text { Normalized springback } \\ & \end{array}$

\section{References}

Haupt, S. E. Haupt, R.L. 2004. Practical genetic algorithms-2nd edition. John Wiley \& Sons, Inc., chapter 1.

Manesh H.D., Taheri A.K. 2003. Bond strength and formability of an aluminum-clad steel sheet. Journal of Alloys and Compounds, Vol. 361, pp.138-143.

De-hua H., LI Dong-sheng, LI Xiao-qiang, JIN Chao-hai 2010. Optimization on springback reduction in cold stretch forming of titanium-alloy aircraft skin. Transaction of Nonferrus Metals of China, Vol.20, pp.2350-2357.

Ito, K., Kasajima, M. and Furuya, S. 1981. Bending and springback theory of metal-polymer sandwich laminates. Journal of Macromolecular Science, Part B, Vol.19, Issue 4, pp.773-791. 
Yilamu K., Hino R., Hamasaki H., Yoshida F. 2010. Air bending and springback of stainless steel clad aluminum sheet. Journal of Materials Processing Technology, Vol.210, Issue 2, pp. 272-278

Sousa L.C., Castro C.F., Antonio C.A.C. 2006. Optimal design of V and U bending processes using genetic algorithms. Journal of Materials Processing Technology, Vol.172, pp.35-41.

Liu L., Wang J. 2004. Modeling Springback of metal-polymer-metal laminates. Journal of Manufacturing Science and Engineering, Vol. 126, pp.599-604.

Marciniak Z, Duncan J. 1992. Mechanics of sheet metal forming. Great Britain: Edward Arnold, Chap. 6, pp 82-106.

MATLAB Genetic Algorithm and Direct Search Toolbox User's Guide, 2006.

Parsa M. H., Yamaguchi K., Takakura N. 2001. Redrawing analysis of aluminum-stainless-steel laminated sheet using FEM simulations and experiments. International Journal of Mechanical Sciences, Vol.43, pp.2331-2347.

Rao M.D. 2003. Recent applications of viscoelastic damping for noise control in automobiles and commercial airplanes. Journal of Sound and Vibration, Vol.262, pp.457-474.

Hino R., Goto Y., Yoshida F. 2003. Springback of sheet metal laminates in draw-bending. Journal of Materials Processing Technology, Vol.139, pp.341-347.

Yuen W.Y.D. 1996. A generalised solution for the prediction of springback in laminated strip. Journal of Materials Processing Technology, Vol.61, pp.254-264.

\section{Biographical notes}

S.V.Mohammadi graduated in Mechanical Engineering from Iran University of Science and Technology (IUST), Iran in 2008 and received his Master Degree in Mechanical Engineering (Manufacturing) from School of Engineering and Hi-tech, Iran University of Industries and Mines in 2011. He is presently working as a member of Simulation Laboratory in the Department of Material Science and Engineering in University of Tehran.

Dr. M. H. Parsa is a professor of Material Science and Engineering, College of Metallurgy and Materials engineering, University of Tehran, Iran. He graduated in Metallurgy and Materials engineering from Sharif University of Technology, Tehran, Iran in 1984. He received his Master Degree from Sharif University of Technology, Tehran, Iran in 1988. He received his Doctor of Engineering from Kyoto Institute of Technology, Kyoto, Japan in 1993. He has done many industry related projects. He published 43 papers in various International and National Journals and 90 papers in International/ National Conferences. His areas of Interests are Metal forming simulation, Glass forming simulation, Phase transformation simulation, manufacturing processes.

Dr. A. Jalali Aghchai is currently an Assistant Professor in School of Engineering and Hi-tech, Iran University of Industries and Mines. He graduated in Mechanical Engineering from Amirkabir University, Iran in 2001. He received his Masters Degree from Amirkabir University, Iran in 2004. He received PhD from Amirkabir University, Iran in 2009. He has published over 7 research papers in refereed journals and conference proceedings.

Received March 2011

Accepted June 2011

Final acceptance in revised form July 2011 